\title{
Al-Induced One Dimensional Nano-Facet Formation on Si(113) Surface *
}

\author{
Masashi Mino, ${ }^{\dagger}$ Hitoshi Nakahara, and Yahachi Saito \\ Department of Quantum Engineering, Nagoya University, Furo-cho, Chikusa-ku, Nagoya 464-8603, Japan \\ Hidetoshi Suzuki \\ Super-High Efficiency Photovoltaic Research Center, Toyota Technological Institute, \\ 2-12-1 Hisakata, Tempaku-ku, Nagoya 468-8511, Japan \\ (Received 26 November 2007; Accepted 17 January 2008; Published 9 February 2008)
}

\begin{abstract}
We have studied surface morphology and surface reconstruction of an $\mathrm{Al}$ adsorbed $\mathrm{Si}(113)$ surface using a scanning tunneling microscope. A clean $\mathrm{Si}(113)$ surface is atomically flat, but well-ordered one-dimensional (1D) nano-facet structures with their width of about $2.5 \mathrm{~nm}$ are formed on this surface after $1 \mathrm{ML}$ of $\mathrm{Al}$ deposition. In the faceting process, the initial stage is $\mathrm{Al}$ atoms replacement with $\mathrm{Si}$ atoms at $0.4 \mathrm{ML}$ of $\mathrm{Al}$ deposition. Replaced $\mathrm{Si}$ atoms stick to steps, causing the change of steps shape. These Si atoms also form two-dimensional (2D) islands. The next stage is growth of $2 \mathrm{D}$ islands toward [3 $3 \overline{3} 2]$ direction at $0.6 \mathrm{ML}$ of $\mathrm{Al}$ deposition. At this coverage, $2 \mathrm{D}$ islands consist of $(\overline{9} 61),(6 \overline{9} 1)$, and $(33 \overline{2})$ steps. For further $\mathrm{Al}$ deposition, $(\overline{9} 61)$ and $(6 \overline{9} 1)$ steps become unstable and $(33 \overline{2})$ and $(\overline{3} \overline{3} 2)$ steps become stable. Finally, $(33 \overline{2})$ and $(\overline{3} \overline{3} 2)$ steps change into two kinds of nano-facet structures, i.e. (112) and (115) facets. On the (112) facet, a mixture of $N \times 1$ structures $(N=3-8)$ is observed. The most abundant value of $N$ is 6 , which well agrees with the first principle calculation. While on the (115) facet, $4 \times 1$ structures are observed. [DOI: 10.1380/ejssnt.2008.45]
\end{abstract}

Keywords: Scanning tunneling microscopy; Aluminum; Silicon; High index single crystal surfaces; Surface structure, morphology, roughness, and topography; Si(113) surface; Facet

\section{INTRODUCTION}

Semiconductor surfaces with or without adsorbates have been studied as suitable playgrounds to study the phase transition of the surfaces. These studies mostly focus on low-indexed surfaces such as (100) or (111). Since they concern various kinds of indexed Si surface, they offer fundamental knowledge in surface physics. Several studies on high-indexed surfaces, on the other hand, have been carried out recently [1-4] as candidates for stages to form self-organized nano-structures because of their lower symmetry than (100) or (111) surfaces. Studies of metal adsorbed high-indexed surfaces are important from an industrial point of view as well as a scientific point of view. A clean $\mathrm{Si}(113)-3 \times 2$ surface is well known to be atomically-flat and energetically stable $[5,6]$. Authors found that $\mathrm{Ga}$ deposition on a $\mathrm{Si}(113)$ surface induced well-ordered one-dimensional (1D) nano-facet structures spontaneously, which was composed of (112) and (115) surfaces [7]. Group-III Al atoms are less likely to diffuse on the surface compared with the same group-III Ga atoms. Ji et al. [8] reported that $\mathrm{Al}$ deposition on a $\mathrm{Si}(113)$ surface leaded faceting formation of (103), (013), (112), and (115) surfaces. The mechanism of faceting formation and details of facet structures on an $\mathrm{Al}$ absorbed $\mathrm{Si}(113)$ surface, however, have not been revealed yet. Soref [9] demonstrated that $\mathrm{Al}$ could act as a p-type dopant for single-crystal Si. Assuming that the Al deposition leads to form the nano-facet structure on a $\mathrm{Si}(113)$ surface voluntarily, it is expected that the self-assembled nano-scale quantum wire can be acquired. Also supposing $\mathrm{Al}$ leads to the same facet formation as $\mathrm{Ga}$, faceting

*This paper was presented at 6th International Symposium on Atomic Level Characterizations for New Materials and Devices, Kanazawa, Japan, 28 October-2 November, 2007.

$\dagger$ Corresponding author: mino@surf.nuqe.nagoya-u.ac.jp mechanism of III/IV systems might be generalized.

In this work, surface morphology change and surface reconstruction of an $\mathrm{Al}$ adsorbed $\mathrm{Si}(113)$ surface were investigated using a scanning tunneling microscope (STM).

\section{EXPERIMENTAL}

All experiments were performed in an ion-pumped ultrahigh vacuum chamber having a base pressure below $1 \times 10^{-8} \mathrm{~Pa}$ equipped with optics for STM. Details of this apparatus were described elsewhere [7]. The singlecrystalline substrate used in our experiment was $\mathrm{P}$ doped n-type with a resistivity of $2.4-4.2 \Omega \cdot \mathrm{cm}$ and oriented within $0.1^{\circ}$ from (113) direction. The sample was cleaned in acetone in an ultrasonic bath before introduced into ultrahigh vacuum chamber. Then it was outgassed by heating at $500^{\circ} \mathrm{C}$ for 12 hours and flashed up to $1200^{\circ} \mathrm{C}$ for a few seconds. The sample was heated by direct current and its temperature was measured by the IR thermometer. The $\mathrm{Al}$ deposition source was a droplet of $\mathrm{Al}$ placed in an AlN K-cell. The $\mathrm{Al}$ deposition rate was estimated from the coverage at which the $\mathrm{Al} / \mathrm{Si}(111)-\sqrt{3} \times \sqrt{3}$ reconstruction appeared [10]. Typical Al deposition rate was $0.1 \mathrm{ML} / \mathrm{min}$. The pressure during the $\mathrm{Al}$ deposition was maintained at $1 \times 10^{-7} \mathrm{~Pa}$. To prevent the decay of surface structures, the sample was cooled down to room temperature (RT) as soon as the $\mathrm{Al}$ deposition was finished. All STM images were taken at RT. As for the way STM images ware taken, they were not taken consecutively. Therefore, the same area was not observed in a series of STM images.

\section{RESULTS AND DISCUSSION}

Figure 1 shows STM images of (a) a clean $\mathrm{Si}(113)-3 \times 2$ surface and (b) a $1.0 \mathrm{ML}$ of $\mathrm{Al}$ adsorbed $\mathrm{Si}(113)$ surface prepared at $550^{\circ} \mathrm{C}$. As shown in Fig. 1(a), a clean 


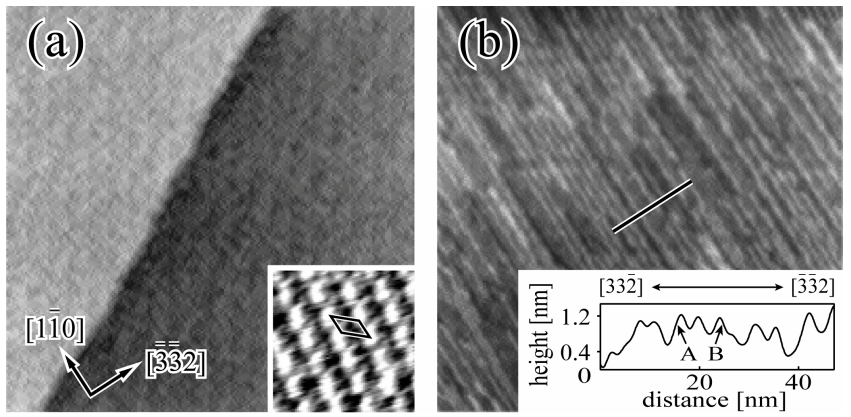

FIG. 1: $200200 \mathrm{~nm}^{2}$ STM images of (a) the clean $\mathrm{Si}(113)$ surface and (b) the 1.0 ML of $\mathrm{Al}$ adsorbed $\mathrm{Si}(113)$ surface at the substrate temperature of $550^{\circ} \mathrm{C}$. These images were taken at constant current mode. STM measurement conditions for these images are: (a) $V_{\mathrm{S}}=1.80 \mathrm{~V}, I=0.20 \mathrm{nA}$ and (b) $V_{\mathrm{S}}=1.60 \mathrm{~V}, I=0.20 \mathrm{nA}$, where $V_{\mathrm{S}}$ is sample voltage and $I$ is tunneling current. The inset within (a) is an expanded $8.2 \times 8.2 \mathrm{~nm}^{2}$ STM image of (a), which displays $3 \times 2$ reconstruction. A cross section taken along a marked line in (b) is shown at the lower right in (b). ' $A$ ' and ' $\mathrm{B}$ ' faces are tilted from (113) toward $[33 \overline{2}]$ and $[\overline{3} \overline{3} 2]$ by $10 \pm 1^{\circ}$ and $11 \pm 2^{\circ}$, respectively.

$\mathrm{Si}(113)$ surface is almost atomically flat, which has only one atomic step along [3̄32] direction in a $200 \times 200 \mathrm{~nm}^{2}$ region. From this step density, a tilt angle of the surface from (113) direction is estimated at about $0.05^{\circ}$. This flat surface is entirely covered with one-dimensional (1D) structures with their width of about $2.5 \mathrm{~nm}$ after 1.0 ML of $\mathrm{Al}$ deposition (Fig. 1(b)). A cross section measured along a diagonal in Fig. 1(b) is shown at the lower right in Fig. 1(b). From the cross section, the surface apparently changes to a faceted surface composed of two faces (here one is represented ' $\mathrm{A}$ ' and the other ' $\mathrm{B}$ '). A tilt angle of the ' $\mathrm{A}$ ' facet is $10 \pm 1^{\circ}$ from the (113) surface toward $[33 \overline{2}]$ and that of the ' $\mathrm{B}$ ' facet is $11 \pm 2^{\circ}$ toward [ $\left.\overline{3} \overline{3} 2\right]$. Each facet has $1.2-1.3 \mathrm{~nm}$ widths. From the measured tilt angle, the 'A' surface is assumed to be (112) facet whose tilt angle between (113) and (112) is $10^{\circ}$. On the other hand, index of the ' $\mathrm{B}$ ' surface cannot be determined only from the analysis of the tilt angle because both (115) and (116) surfaces can meet the measured tilt angle (tilt angles between (113) and $(115) /(116)$ are $\left.9.4^{\circ} / 12^{\circ}\right)$. The (115) and (116) surfaces, however, have a different aspect in the length of a $1 \times 1$ unit cell along [3̄32] direction. An expanded STM image of Fig. 1(b) is shown in Fig. 2. This is a differential current image in which logarithmic differential current is imaged. This type of image is useful to emphasize surface reconstruction on tilt faces. From Fig. 2, the length of a $1 \times 1$ unit cell along [ $\overline{3} \overline{3} 2]$ direction of the ' $\mathrm{B}$ ' face is obtained as $1 \mathrm{~nm}$, which well agrees with that of a (115) $1 \times 1$ unit cell $(0.94 \mathrm{~nm})$, but not agree with that of a (116) $1 \times 1$ unit cell $(2.3 \mathrm{~nm})$. Thus, the ' $\mathrm{B}$ ' surface is determined as (115) facet. As for phase boundary of (112) and (115) facets, it is assumed to have low energy due to short-range order of their widths.

Figure 2 also shows surface reconstructions of (112) and (115) facets. On the (112) facet, $N \times 1$ structures $(N=3-8)$ are observed with $6 \times 1$ one most abundant $(5 \times 1,6 \times 1$ and $7 \times 1$ reconstructions are showed in Fig. 2 ). While on the (115) facet, only $4 \times 1$ structures are observed. Abundance for $N \times 1$ structures on the (112) facet, which is obtained by experiment, is shown in Fig. 3 as a bar graph. Baski et al. [11] reported that a Ga adsorbed $\operatorname{Si}(112)$ surface formed $N \times 1$ structures $(N=4$ 7). They proposed a structural model of a $\mathrm{Ga} / \mathrm{Si}(112)$ surface, which is a Ga vacancy model. Their model well agrees with the image contrast of our $N \times 1$ units shown in Fig. 2. We perform the first-principles total energy calculations for an $\mathrm{Al}$ vacancy model, in which Ga atoms of Baski's model are replaced with $\mathrm{Al}$ atoms. In the calculation, a (112) slab geometry is composed of four layers of $\mathrm{Si}$ and one vacuum layer, which is equivalent to three layers of $\mathrm{Si}$, with the same single $N \times 1$ unit cell in each slab surface. The calculations are performed within LocalDensity-Approximation (LDA), using Troullier-Martins pseudopotentials and a plane wave basis with a kinetic energy cutoff of 12 Ha. For structural relaxation, cycles of each calculation continue until two consecutive evaluations of the total energy differ by less than $5.0 \times 10^{-5} \mathrm{Ha}$. Furthermore, we compute surface free energy per unit cell, $E_{\text {suf }}(N)$ with $N$ range from 3 to 8 :

$$
E_{\text {suf }}(N)=\left[E_{\text {tot }}(N)-n_{\mathrm{Al}} E_{\mathrm{Al}}-n_{\mathrm{Si}} E_{\mathrm{Si}}\right] /(2 A),
$$

where $A$ is the surface area of $N \times 1$ unit cell, $E_{\text {tot }}(N)$ the total energy, $n_{\mathrm{Al} / \mathrm{Si}}$ the number of $\mathrm{Al} / \mathrm{Si}$ atoms, $E_{\mathrm{Al} / \mathrm{Si}}$ the chemical potential of $\mathrm{Al} / \mathrm{Si}$ atoms. The calculated relative surface energy is shown in Fig. 3 in addition to the abundance of $N \times 1$ structures (the relative surface energy is defined as $\left.E_{\text {suf }}(N)-E_{\text {suf }}(6)\right)$. The calculation agrees with the experiment qualitatively. We conclude, therefore, that surface energy is predominant in formation of surface reconstruction on the (112) facet. The calculation, however, does not agree with the experiment in respect of $5 \times 1$ or $8 \times 1$ unit cell. This suggests that only surface energy does not determine surface periodicity. Following causes are considered for the disagreement between experiment and calculation. First, there is a possibility that abundance of $N \times 1$ structures did not reach the equilibrium state in the experiment, which means the lack of kinetic energy of $\mathrm{Si}$ or $\mathrm{Al}$ atoms to form the reconstructions. Second, effect of edges for mixed $N \times 1$ structures was ignored in the calculations because only single kind of $N \times 1$ structure consisted of the surface in each calculation. Third, the calculations were carried out for flat surfaces, not for faceted surfaces. Thus it is considered that dynamics or kinetics may contribute to formation of $N \times 1$ structures.

As mentioned above, 1.0 ML of $\mathrm{Al}$ deposition induces 1D facet structures on a $\mathrm{Si}(113)$ surface. Then details of the faceting process should be noted. Figure 4 shows a faceting process of an $\mathrm{Al} / \mathrm{Si}(113)$ surface at the substrate temperature of $550^{\circ} \mathrm{C}$. At $0.4 \mathrm{ML}$ of $\mathrm{Al}$ deposition (Fig. 4(a)), almost straight step of a clean $\mathrm{Si}(113)$ surface becomes rough, which indicates a decline of step stiffness. Additionally a two-dimensional (2D) island that is pointed out by an arrow in Fig. 4(a) nucleates on a terrace. Surface reconstruction on the $2 \mathrm{D}$ island is $2 \times 2$ structure, which is the same as that on the terrace. This implies that $\mathrm{Al}$ atoms replace with $\mathrm{Si}$ atoms, resulting in the increase of density of Si atoms diffusing on the surface. It is considered that change of the step shape is caused by these excess Si atoms sticking to the step. The 2D island is observed within $50 \mathrm{~nm}$ apart from a neighboring step, which indicates that the diffusion length of a Si atom on 


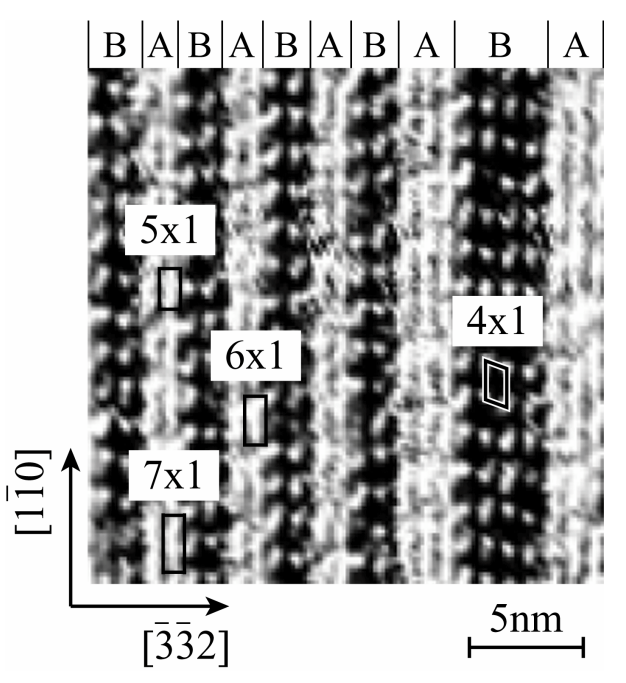

FIG. 2: An expanded differential current STM image of the surface shown in Fig. 1(b). White rows showed as 'A' correspond to (112) facets and black rows showed as 'B' (115) facets. Black rectangles on (112) facets indicate $N \times 1$ structures $(N=$ $5-7)$. A black parallelogram on a (115) facet indicates a $4 \times 1$ structure.

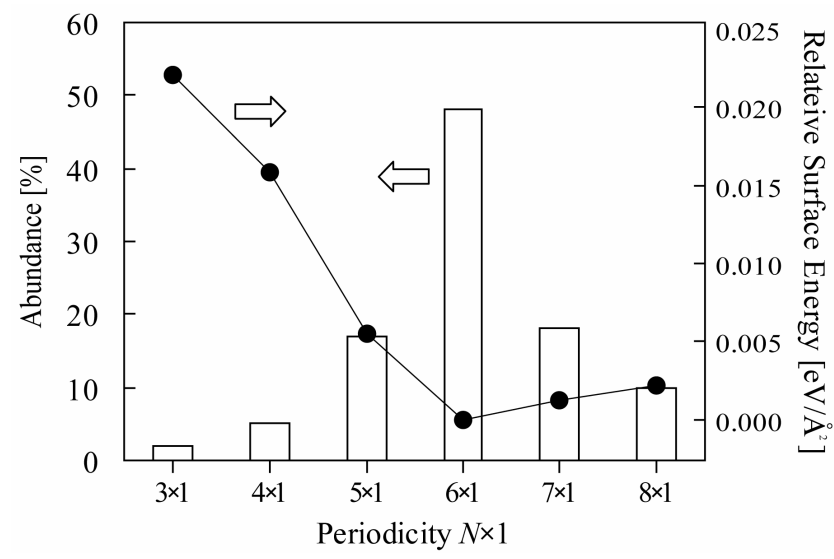

FIG. 3: Bars show an abundance of $N \times 1$ structures on (112) facets measured from STM images. A line shows calculated surface energy for each $N \times 1$ unit area plotted as a function of vacancy periodicity $N$. The surface energy is relative to that for $6 \times 1$ period. The atomic model used for the calculation is an $\mathrm{Al}$ vacancy model, in which Ga atoms of Baski's Ga vacancy model are replaced with $\mathrm{Al}$ atoms [11].

the surface is about $50 \mathrm{~nm}$. The $2 \mathrm{D}$ islands grow toward $[\overline{3} \overline{3} 2]$ direction and most of them have two or three layers height at 0.6 ML of Al deposition (Fig. 4(b)). The shape of $2 \mathrm{D}$ islands looks like isosceles triangle especially for the highest ones. These 2D islands consist of $(\overline{9} 61),(6 \overline{9} 1)$, and $(33 \overline{2})$ steps. These steps are assumed to be stable at this coverage. For further deposition of $\mathrm{Al},(\overline{9} 61)$ and (6⿳亠口冋1) steps become unstable and $(33 \overline{2})$ and $(\overline{3} \overline{3} 2)$ steps become stable, which results in the formation of 1D-like structures as indicated by an ellipse in Fig. 4(c). At $0.9 \mathrm{ML}$ of Al deposition (Fig. $4(\mathrm{~d})),(33 \overline{2})$ and $(\overline{3} \overline{3} 2)$ steps changes into (112) and (115) facets, and 1D-like structures cover almost throughout the surface. Thus stable step or facet is different at different amount of $\mathrm{Al}$ deposition.

The faceting process that (112) and (115) facet structures are formed on a $\mathrm{Si}(113)$ surface by $\mathrm{Al}$ deposition is

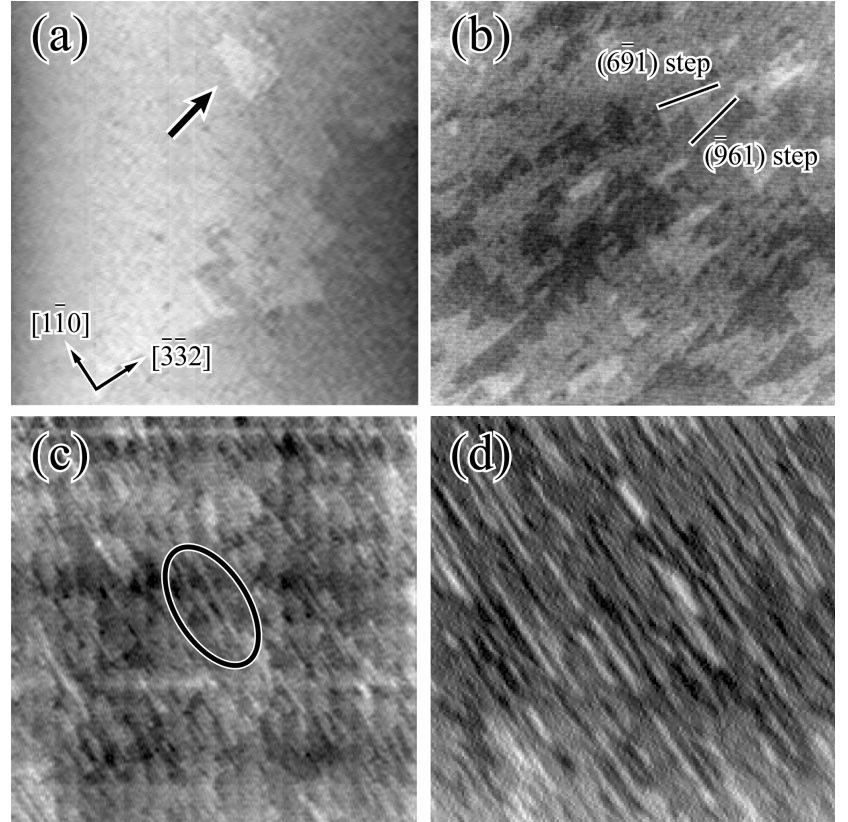

FIG. 4: $200 \times 200 \mathrm{~nm}^{2}$ STM images of the $\mathrm{Al}$ adsorbed $\mathrm{Si}(113)$ surface at the substrate temperature of $550^{\circ} \mathrm{C}$. Al coverage is (a) $0.4 \mathrm{ML}$, (b) $0.6 \mathrm{ML}$, (c) $0.8 \mathrm{ML}$, and (d) $0.9 \mathrm{ML}$. All images were taken at constant current mode. An arrow in (a) indicates a 2D island on a terrace. In (b), 2D islands consist of $(\overline{9} 61),(6 \overline{9} 1)$, and $(33 \overline{2})$ steps. An ellipse in (c) shows an area where 1D-like structures are formed.

similar to that of (112) and (115) facets induced by Ga deposition [7]. The surface reconstructions on (112) and (115) facets are also the same. Therefore group-III metals might induce $1 \mathrm{D}$ facet structures on a $\mathrm{Si}(113)$ surface with the same mechanism. The substrate temperature at which facets are formed by $\mathrm{Al}$ deposition is, however, about $100^{\circ} \mathrm{C}$ higher than the case of $\mathrm{Ga}$ deposition. Also the isosceles triangle-like $2 \mathrm{D}$ island which is formed at $0.6 \mathrm{ML}$ of $\mathrm{Al}$ deposition is somewhat distorted compared with that formed by Ga deposition. These differences imply that Si atoms needed to form the facet structures are urged to move by $\mathrm{Al}$ atoms less efficiently than Ga atoms.

\section{SUMMARY}

Surface morphology and surface reconstruction of an Al adsorbed $\mathrm{Si}(113)$ surface has been investigated using a STM. It is found that $\mathrm{Al}$ deposition on a $\mathrm{Si}(113)$ surface induces one-dimensional (1D) nano-facet structures, which is composed of (112) and (115) facets with each facet width of $1.2-1.3 \mathrm{~nm}$. On the (112) facet, $N \times 1$ structures are observed. The value of $N$ ranges from 3 to 8 with most abundant 6 , which roughly agrees with the first-principle total energy calculation. There is, however, disagreement for $5 \times 1$ or $8 \times 1$ period. Therefore it is considered that surface energy is predominant in the $N \times 1$ surface reconstruction on the (112) facet, but kinetics or dynamics relate to that. While on the (115) facet, $4 \times 1$ structures are observed. Phase boundary of these two facets is assumed to have low energy because they have short-range order widths. The faceting process at the substrate temperature of $550^{\circ} \mathrm{C}$ is as follows: The 
initial stage is $\mathrm{Al}$ atoms replacement with $\mathrm{Si}$ atoms at $0.4 \mathrm{ML}$ of $\mathrm{Al}$ deposition. Replaced Si atoms lead to the change of step shape by sticking to the step and the nucleation of a two-dimensional (2D) island. Then the 2D islands grow toward $[\overline{3} \overline{3} 2]$ direction and piled up at 0.6 $\mathrm{ML}$ of $\mathrm{Al}$ deposition. The $2 \mathrm{D}$ islands look like isosceles triangles, which consist of $(\overline{9} 61),(6 \overline{9} 1)$, and $(33 \overline{2})$ steps and form $2 \times 2$ reconstruction. For further $\mathrm{Al}$ deposition, $(\overline{9} 61)$ and $(6 \overline{9} 1)$ steps become unstable, instead $(33 \overline{2})$ and $(\overline{3} \overline{3} 2)$ steps become stable, resulting in 2D islands elongation toward [1ํㅣㄹ direction. At $0.9 \mathrm{ML}$ of $\mathrm{Al}$ deposition, $(33 \overline{2})$ and $(\overline{3} \overline{3} 2)$ steps change into (112) and (115) facets. Thus 1D facet structures are formed, and this faceting process of an $\mathrm{Al} / \mathrm{Si}(113)$ surface is almost the same as that of a $\mathrm{Ga} / \mathrm{Si}(113)$ surface. Therefore faceting process of a group-III metal adsorbed $\mathrm{Si}(113)$ surface might be generalized.

\section{Acknowledgments}

The authors wish to thank all members of Machinery Center of Applied Physics, Nagoya University for their help on improving experimental equipment.
[1] M. Kumar, V. K. Paliwal, A. G. Joshi, Govind, and S. M. Shivaprasad, Surf. Sci. 596, 206 (2005).

[2] T. Ding, J. Zhang, Y-Q. Ma, L. Zeng, and Y-k. Chen, Colloids Surf. A 284-285, 567(2006).

[3] Y. Temko, T. Suzuki, and K. Jacobi, Appl. Phys. Lett. 82, 2142 (2003).

[4] H. Minoda, T. Shimakura, K. Yagi, F. J. M. zu Heringdorf, and M. H. von Hoegen, Surf. Sci. 432, 69 (1999).

[5] T. Suzuki, Y. Tanishiro, H. Minoda, K. Yagi, and M. Suzuki, Surf. Sci. 298, 473 (1993)

[6] J. M. Gibson, M. L. McDonald, and F. C. Unterwald,
Phys. Rev. Lett. 55, 1765 (1985).

[7] H. Suzuki, H. Nakahara, S. Miyata, and A. Ichimiya, Surf. Sci. 493, 166 (2001).

[8] H. Ji, R. G. Zhao, and W. S. Yang, Surf. Sci. 371, 349 (1997).

[9] R. A. Soref, J. Appl. Phys. 38, 5201 (1967).

[10] T. Ide, T. Nishimori, T. Tani, and T. Ichinokawa, Surf. Sci. 216, 189 (1989).

[11] A. A. Baski, S. C. Erwin, and L. J. Whitman, Surf. Sci. 423, L265 (1999). 